\title{
PROPUESTAS PARA LA MEJORA DE LA REGULACIÓN LEGAL SOBRE EL DERECHO A LA DESCONEXIÓN DIGITAL
}

\author{
Daniel Monera Bernabéu \\ Doctor en derecho y sociedad \\ Universidad a distancia de Madrid-UDIMA
}

\begin{abstract}
En el contexto actual la falta de concreción normativa y el carácter meramente programático que se hace del derecho a la desconexión digital dentro del Real Decreto legislativo 2/2015, de 23 de octubre, del Estatuto de los Trabajadores y su no inclusión en la Ley 31/1995, de 8 de noviembre, de prevención de riesgos laborales, redirigen hacia la Ley Orgánica 3/2018, de 5 de diciembre, de Protección de Datos Personales y garantía de los Derechos Digitales -LOPDPGDD- (centrada, además, en la protección de datos de carácter personal), de donde derivan otros aspectos controvertidos como son la ausencia de un concepto preciso, el hecho de dejar su delimitación a lo que pueda fijarse en la negociación colectiva o el no proporcionar unas pautas-guías mínimas de referencia para facilitar u orientar la política interna a elaborar por las empresas, de ahí, que se estima necesario sugerir previsiones acabadas para su incorporación en los dos primeros textos en armonía con la LOPDPGDD.
\end{abstract}

In the current context, the lack of normative concretion and the merely programmatic nature of the right to digital disconnection within Royal Legislative Decree 2/2015, of October 23, of the Workers' Statute and its non-inclusion in Law 31 / 1995, of November 8, on the prevention of occupational risks, redirect to Organic Law 3/2018, of December 5, on the Protection of Personal Data and guarantee of Digital Rights -LOPDPGDD(also focused on the protection of personal data), from which other controversial aspects derive such as the absence of a precise concept, the fact of leaving its delimitation to what can be set in collective bargaining or not providing minimum reference guidelines-guides to facilitate or guide the internal policy to be elaborated by the companies, hence, it is deemed necessary to suggest completed forecasts for their incorporation in the first two texts in harmony with the LOPDPGDD.

Title: Proposals for the improvement of the legal regulation on the right to digital disconnection

IUSLabor 3/2021, ISSN 1699-2938, p. 8-30

DOI. 10.31009/IUSLabor.2021.i03.01 
Palabras clave: condiciones de trabajo, situaciones laborales, desconexión digital. Keywords: Status of workers; occupational hazards; digital disconnect.

Fecha envío: 29.4.2021 | Fecha aceptación: 26.5.2021

\section{Sumario}

1. Propuestas de lege ferenda para la actualización de la normativa laboral común

2. La regulación de la desconexión digital en el Estatuto de los Trabajadores

3. Incisos digitales en la normativa de prevención de riesgos laborales

4. Conclusiones

5. Bibliografía 


\section{Propuestas de lege ferenda para la actualización de la normativa laboral común}

El Pleno del Congreso de los Diputados, en su sesión del 18 de octubre de 2018, aprobó el Proyecto de LOPDPGDD ${ }^{1}$, ratificado, sin introducir en él ninguna modificación, un mes y tres días después por el Pleno del Senado ${ }^{2}$. El resultado final será la Ley Orgánica 3/2018, de 5 de diciembre, de Protección de Datos Personales y garantía de los Derechos Digitales (LOPDPGDD) ${ }^{3}$. Esta norma, entre otras circunstancias, refleja la conciencia existente sobre la necesidad de proporcionar una respuesta legislativa al fenómeno, creciente e incesante, de intensa conectividad de los trabajadores con sus entornos profesionales, responsable del conocido como "trabajo sin fin" 4 , tan característico en la actualidad.

De todas formas, este texto lo que esencialmente pretende es lograr la adaptación del ordenamiento jurídico español al Reglamento (UE) 2016/679, del parlamento europeo y del consejo relativo a la protección de las personas físicas en lo que respecta al tratamiento de datos personales -RGPD- ${ }^{5}$, proporcionando así una base sólida y actualizada sobre la que establecer las garantías precisas para el tratamiento y la libre circulación de los datos personales. No obstante y conforme a lo dispuesto en el artículo 18.4 de la CE, en paralelo también busca tutelar los derechos digitales de los ciudadanos $^{6}$. De ahí esa estructura bicéfala de la que hace gala: la primera, compuesta por sus Títulos I al IX; la segunda, en cambio, por el Título X y sus diecinueve artículos (del 79 al 97), siendo el más relevante de ellos, dadas las coordenadas en las que se mueve este artículo, el precepto número 88, que si bien "reconoce el derecho a la desconexión digital, [...] -en última instancia- no lo define ni establece garantías de efectividad del mismo"7.

El referido artículo 88 de la LOPDPGDD está claramente dirigido a tratar de limitar la disponibilidad tecnológica a la que diariamente se encuentran sometidos muchos empleados, intentando también asegurar que se respeten los tiempos de descanso y que

\footnotetext{
${ }^{1}$ Ref. no 121/000013 (BOCG. Congreso de los Diputados, serie A, nº 13-6, de 26 de octubre de 2018).

${ }^{2}$ Ref. $n^{\circ} 621 / 000012$ (BOCG. Senado, apartado I, no 306-2361, de 26 de noviembre de 2018).

${ }^{3}$ BOE n $^{\circ} 294$, de 6 de diciembre.

${ }^{4}$ OIT: Informe de la Comisión de Expertos en Aplicación de Convenios y Recomendaciones (artículos 19, 22 y 35 de la Constitución), Informe III (Parte B), Garantizar un tiempo de trabajo decente para el futuro, ob cit., párrafo 746.

${ }^{5}$ DOUE ${ }^{\circ} \mathrm{L} 119 / 1$, de 4 de mayo.

${ }^{6}$ Punto V del Preámbulo de la LOPDPGDD.

${ }^{7}$ Crítica con esta circunstancia, MiÑARRO YANINI, Margarita, "La desconexión digital en la práctica negocial: más forma que fondo en la configuración del derecho", Revista de Trabajo y Seguridad Social $(C E F), \mathrm{n}^{\mathrm{o}} 440,2019$, p. 6.
} 
se posibilite la conciliación de las vidas personal, familiar y laboral ${ }^{8}$; todo lo cual, en su conjunto, va a redundar positivamente en la salud física y mental de los asalariados, y de forma concreta "sobre la afectación de la hiperconectividad", especialmente en entredicho dentro de contextos tan singulares como los del trabajo a distancia y el teletrabajo ${ }^{10}$.

Por otra parte, a pesar de su consabida relevancia para el correcto desarrollo de las relaciones entre los empresarios y los empleados a su servicio, llama la atención que, en el circunscrito contexto de la desconexión digital, el Real Decreto legislativo 2/2015, de 23 de octubre $(E T)^{11}$ y la Ley 31/1995, de 8 de noviembre (LPRL) ${ }^{12}$ destaquen por carecer de una regulación específica (más allá de una sucinta referencia al derecho en el primero de ellos). Este vacío ha conducido a una heterogénea y dispar autorregulación colectiva, excesivamente parca en múltiples ocasiones como consecuencia de no abordar con la profundidad y el rigor requeridos las notables garantías que subyacen, a pesar de su carácter formal y programático, en los artículos 88 de la Ley Orgánica 3/2018, de 5 de diciembre, de Protección de Datos Personales y garantía de los Derechos Digitales (LOPDPGDD) ${ }^{13}$ y 18 de la Ley 10/2021, de 9 de julio, de trabajo a distancia ${ }^{14}$.

\footnotetext{
${ }^{8}$ Apuntando que el derecho a la desconexión se marcó como una primera vía de progreso para impedir que los límites del trabajo y del descanso siguieran desdibujándose, OIT: Informe de la Comisión de Expertos en Aplicación de Convenios y Recomendaciones (artículos 19, 22 y 35 de la Constitución), Informe III (Parte B), Garantizar un tiempo de trabajo decente para el futuro, ob cit., párrafo 758.

${ }^{9}$ MiÑarro YANINI, Margarita, "El sistema de prevención de riesgos laborales como garantía de efectividad del derecho a la desconexión digital", Vigilancia y control en el Derecho del Trabajo Digital, en Rodríguez-PiÑERo Royo, Miguel y Todolí Signes, Adrián, (Directores), Pamplona (Thomson Reuters-Aranzadi), 2020, p. 578.

${ }^{10}$ FERNÁNDEZ-COSTALES MUÑIZ, Javier, "La prevención de riesgos laborales y sus nuevas exigencias y retos frente al avance de la digitalización y las nuevas tecnologías", Revista de Trabajo y Seguridad Social (CEF), nº 452, 2020, p. 100.

${ }^{11}$ Real Decreto Legislativo 2/2015, de 23 de octubre, por el que se aprueba el texto refundido de la Ley del Estatuto de los Trabajadores (BOE $\mathrm{n}^{\circ} 255$, de 24 de octubre).

${ }^{12}$ Ley 31/1995, de 8 de noviembre, sobre prevención de riesgos laborales (BOE ${ }^{\circ} 269$, de 10 de noviembre).

${ }^{13} \mathrm{BOE}^{\circ} 294$, de 6 de diciembre.

${ }^{14} \mathrm{BOE} \mathrm{n}^{\circ} 164$, de 10 de julio.

Es lo que, por ejemplo, "sucede con el régimen relativo a la desconexión digital prevista en el Convenio colectivo de Telefónica -que- tampoco garantiza necesariamente ese "justo equilibrio" entre razones de eficacia tecnológica de empresa y razones de protección tecnológica de las personas trabajadoras". El apunte, en MiÑARRo YANINI, Margarita, "La "transición tecnológica sociolaboralmente justa": por una gobernanza colectiva de la digitalización", Revista de Trabajo y Seguridad Social (CEF), n 452, 2020, p. 12.

"Más con la regulación actual del derecho - a la desconexión digital- desde finales de diciembre de 2018, [...], se exige una revisión profunda del derecho y que atienda a los nuevos marcos laborales instaurados en las empresas". Apuntándolo, TRUJILLO PONS, Francisco, "La desconexión digital en el trabajo. Un
} 
En ese sentido, el hecho de que en la actualidad el uso con fines laborales de las tecnologías de la información y de la comunicación (TIC) presente una creciente intensidad que puede traer consigo ventajas como el equilibrio entre las vidas individual, familiar y profesional o una mayor flexibilidad en los tiempos de trabajo y de descanso e inconvenientes ligados a la salud como la fatiga informática y, que el ordenamiento jurídico y la negociación colectiva no estén dando una respuesta adecuada al derecho a la desconexión digital, es causa determinante para proponer un contenido guía- de mínimos en la legislación laboral básica.

Con lo anterior, se conseguiría una propuesta de adaptación de la normativa, un concepto de desconexión digital que agrupe otros derechos o principios fundamentales como la intimidad, la conciliación, los tiempos de trabajo y la salud, unas pautas mínimas y claras para los interlocutores sociales y la base para la elaboración de la política interna de la empresa. Iniciando su camino a partir del ET por haber sido elegido por el propio legislador para incorporar el artículo 20 bis $^{15} \mathrm{y}$, por otra parte, por recoger otras cuestiones conexas con la desconexión digital como los tiempos de trabajo ${ }^{16}$. Asimismo, se conseguiría sacar el derecho objeto de estudio de una Ley Orgánica centrada en la protección de datos, se delimitaría el contenido y se podría evitar que se recogiera de un modo sistemático y genérico, garantizándose en la medida de lo posible su adecuado desarrollo. En último lugar, con la LPRL por remisión del propio artículo 88.3 de la LOPDPGDD en el que se manda al empresario la elaboración de una política interna de empresa dirigida a los trabajadores con acciones de formación y sensibilización sobre el uso razonable de las herramientas tecnológicas para evitar la

comentario a la luz de la sentencia del Tribunal Superior de Justicia de Madrid, de 4 de noviembre de 2020 (rec. 430/2020)", Revista de Derecho Social, no 92, 2021, p. 200.

Así mismo, hay que tener en cuenta que "el derecho a la desconexión digital de los trabajadores [...] no está definido, ni delimitado su contenido por la normativa reguladora del teletrabajo, toda vez que ésta remite a los señalado en la ley reguladora del derecho a la desconexión que, como es sabido, reconoce el citado derecho a la desconexión digital como un derecho autónomo, pero deja en manos de la negociación colectiva y la política interna de la empresa [...], las modalidades de su ejercicio, así como las acciones de formación y sensibilización del personal sobre el uso razonable de las herramientas informáticas". Subrayándolo, PÉREZ CAMPOS, Ana Isabel, "Teletrabajo y derecho a la desconexión digital", Revista Internacional y Comparada de Relaciones Laborales y Derecho del Empleo, vol. 9, $\mathrm{n}^{\circ}$ 1, 2021, p. 502.

15 "Derechos de los trabajadores a la intimidad en relación con el entorno digital y a la desconexión. Los trabajadores y los empleados públicos tendrán derecho a la desconexión digital a fin de garantizar, fuera del tiempo de trabajo legal o convencionalmente establecido, el respeto de su tiempo de descanso, permisos y vacaciones, así como de su intimidad personal y familiar (artículo 20 bis)".

${ }^{16}$ Artículos: 34. Jornada, 35. Horas extraordinarias, 36. Trabajo nocturno, trabajo a turnos y ritmo de

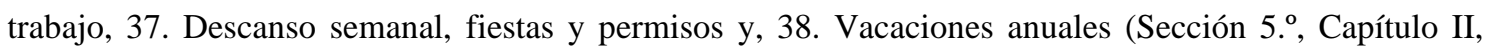
Título I del ET). 
fatiga informática se podría conseguir -con incisos- recoger el derecho en una ley preventiva.

De ahí, que en orden a disponer de un marco normativo más completo, capaz de servir de línea directriz en otros niveles subordinados llamados a completarlo y perfeccionarlo (preferiblemente, es lo que aquí se defiende, el de la negociación colectiva estatutaria ${ }^{17}$ ), se estima necesario intentar sugerir previsiones acabadas para su efectiva incorporación tanto en el ET (de manera principal) como en la LPRL (con un carácter más supletorio $)^{18}$, en sintonía con el carácter ordinario que, pese a todo y junto con otros, la propia LOPDPGDD (disp. final primera) otorga al contenido de su precepto número 88.

\section{La regulación de la desconexión digital en el Estatuto de los Trabajadores}

Sin necesidad de remontarse más atrás en el tiempo, el actual texto refundido del ET vino a integrar en un mismo cuerpo normativo "la pluralidad de disposiciones existentes, dotando de seguridad jurídica y claridad en este dinámico sector de nuestro ordenamiento"19. Sin embargo, a pesar de su relativa modernidad, "sigue huérfano de los derechos fundamentales de los trabajadores en el trabajo y apenas ha tenido noticia de los formidables cambios en las formas de trabajar y organizar la producción y las

\footnotetext{
${ }^{17}$ No en vano, merece la pena recordar que, de acuerdo con el artículo 91 de la LOPDPGDD, "los convenios colectivos podrán establecer garantías adicionales de los derechos y libertades relacionados con el tratamiento de los datos personales de los trabajadores y la salvaguarda de derechos digitales en el ámbito laboral". Sin embargo, no hay que perder tampoco de vista que la misma norma, en su precepto número 88 , abre la posibilidad de determinar las modalidades de ejercicio de este derecho, en defecto de la negociación colectiva, a través de un acuerdo "entre la empresa y los representantes de los trabajadores".

${ }^{18}$ En este contexto, se estima también conveniente la correlativa actualización del artículo 7.5 de la LISOS, centrado en ciertas infracciones graves del empresario en materia de relaciones laborales. En concreto, su nueva redacción podría quedar de la siguiente forma (se destacan en negrita las modificaciones propuestas): "5. La transgresión de las normas y los límites legales o pactados en materia de jornada, trabajo nocturno, horas extraordinarias, horas complementarias, descansos, vacaciones, permisos, registro de jornada, desconexión digital y, en general, el tiempo de trabajo a que se refieren los artículos 12, 23 y 34 a 43 del Estatuto de los Trabajadores".

Análoga suerte podrían correr otros textos normativos, como la Ley 36/2011, de 10 de octubre, reguladora de la jurisdicción social -LRJS- (BOE n 245, de 11 de octubre), para los que, quizás, bastaría con analizar si se han de adaptar algunas de sus previsiones (por ejemplo, la norma procesal laboral incluye una modalidad procesal específica relativa al ejercicio de los derechos en materia de conciliación de las vidas personal, familiar y laboral). Sea como fuere, ello excedería del objeto perseguido en este artículo.

${ }^{19}$ Cruz Villalón, Jesús, García-Perrote Escartín, Ignacio, Goerlich Peset, José María y Mercader Uguina, Jesús Rafael, "La refundición del Estatuto de los Trabajadores de 2015", Actualidad Jurídica Aranzadi, nº 916, 2016, p. 1 (versión digital).
} 
empresas, que han comenzado a fraguarse como consecuencia de la imparable transformación digital" ${ }^{20}$. Buena muestra de ello es cuanto atañe a la garantía del derecho a la desconexión digital, con una raquítica mención en el artículo 20 bis de la norma, sin perjuicio, no obstante, de lo detallada que sí resulta en relación con otros aspectos a tener en cuenta siquiera de forma indirecta, como, verbi gratia, la jornada laboral (artículo 34 ET) o ciertos períodos de descanso (artículos 37 y 38 ET).

Paradójicamente, el RD-L 8/2019 señala en su disposición adicional primera que "el Gobierno, con anterioridad al 30 de junio de 2019, constituirá un grupo de expertos y expertas para llevar a cabo los trabajos y estudios preparatorios para la elaboración de un nuevo Estatuto de los Trabajadores [...] previa audiencia de los interlocutores sociales en la Mesa de Diálogo Social de Empleo y Relaciones Laborales". Sin embargo, y no necesaria o exclusivamente como consecuencia de la actual coyuntura intra (por desgracia, aún no post) COVID-1921, mucho tiempo después todavía sigue pendiente la profunda revisión anunciada sobre el "texto jurídico de referencia central para nuestro sistema de relaciones laborales" 22 . Es más, los desafíos a afrontar como consecuencia de la pandemia han provocado una "dinámica de flujos y reflujos reformadores" 23 con otros enfoques y prioridades, quedando aún ciertos aspectos pendientes como, por ejemplo, "los crecientes retos de la digitalización, del género, -odel trabajo flexible" 24 , los cuales, no resulta ocioso subrayar, han de ir de la mano "en nuestro futuro modelo de relaciones laborales" 25 .

Sea como fuere, ese impasse, unido al vacío legal también apuntado, hace que adquiera un sentido todavía mayor el objetivo principal de este artículo, a saber, ofrecer al lector una propuesta de formulación íntegra y precisa sobre el derecho a la desconexión digital en el actual $\mathrm{ET}^{26}$. Y dado que, sin duda, una inadecuada materialización de la garantía

\footnotetext{
${ }^{20}$ CASAS BAAMONDE, María Emilia, "La significación principal del Estatuto de los Trabajadores en el ordenamiento laboral constitucional”, Trabajo y Derecho, n 63, 2020, p. 19 y 20 (versión digital).

${ }^{21}$ Con carácter previo, algún autor ya auguró que "no parece fácil que se cumpla este plazo". El vaticinio, en CABERo MorÁn, Enrique, “¿Hacia un nuevo Estatuto de los Trabajadores?”, Trabajo y Derecho, no 55, 2019, p. 1 (versión digital).

${ }^{22}$ CruZ Villalón, Jesús, "Hacia un nuevo Estatuto de los Trabajadores", Trabajo y Derecho, no 63, 2020, p. 1 (versión digital).

${ }^{23}$ MiñarRo YAnini, Margarita y Molina NAVARRETE, Cristobal, "El Estatuto de los Trabajadores, 40 años de "reformas" y "maquillados": ¿una conmemoración con sabor a despedida?", Revista de Trabajo y Seguridad Social (CEF), n ${ }^{\circ} 444,2020$, p. 6.

${ }^{24}$ Miñarro YaninI, Margarita y Molina NAVARRETE, Cristobal, "El Estatuto de los Trabajadores, 40 años de "reformas" y "maquillados": ¿una conmemoración con sabor a despedida?", ob cit., p. 19.

${ }^{25}$ CRUZ VILlaLóN, Jesús: "Hacia un nuevo Estatuto de los Trabajadores", ob cit., p. 20 (versión digital).

${ }^{26}$ Sin embargo, procede recordar que el ET "no deja de ser una norma de derechos mínimos que pueden [...] -ser- mejorados en los convenios colectivos". Recuperando esta máxima y enlazándola con la desconexión digital, TRUJILLO PONS, Francisco, "El ejercicio del derecho a desconectar digitalmente del
} 
puede incidir intensa y negativamente en otros ámbitos, como los de la conciliación de las vidas personal, familiar y profesional, la seguridad y la salud en el trabajo o la intimidad.

Se trata de un patrón básico diseñado con el afán de resultar útil y lo más completo posible, aunque sin caer en el error de pretender ofrecer un texto inflexible y necesariamente de mínimos, sin perder de vista que el de la desconexión digital supone un derecho donde prima, si bien no de manera descontrolada, "la voluntad y la disposición individual del propio trabajador, que es el que finalmente decide si quiere o no desconectarse de su trabajo"27.

Así, junto con quirúrgicas, pero significativas, incorporaciones en determinados preceptos (de las que se dará noticia acto seguido), el grueso de las sugerencias será encauzado a través de una inédita y específica sección 6 en el Capítulo II de su Título I (aun cuando quizás lo pertinente sería que el legislador abordara la titánica tarea de modernizar la norma sustantiva, a fin de dotarla de una flexible capacidad de respuesta frente a los vertiginosos avatares del mundo contemporáneo) ${ }^{28}$, para completar un Capítulo del ET en el que se recogen otros derechos y principios fundamentales ligados a la desconexión digital como son la inviolabilidad de la persona del trabajador (artículo 18), la seguridad y salud en el trabajo (artículo 19), los tiempos de trabajo (artículos 34 a 38), etc. Y, que en el caso de aquellas empresas que no cuenten con representantes de los trabajadores se parta de un contenido mínimo y claro para hacer efectivo el derecho.

En primer término, dentro del segundo apartado del artículo 4, relativo a los derechos laborales de las personas trabajadoras, correspondería introducir en el listado una mención expresa al de la desconexión digital, la cual, por qué no, debería ir acompañada de otra referente al desarrollo de acciones de formación y sensibilización sobre un uso responsable de las tecnologías de la información y la comunicación, pues tal labor de concienciación, por mínima que resulte, se antoja imprescindible para la efectividad en

trabajo: su efectividad en las empresas", Lan Harremanak. Revista de relaciones laborales, $\mathrm{n}^{\circ}$ 44, 2020, p. 45.

${ }^{27}$ GARCÍA COCA, Olga, "El registro de la jornada laboral y la privacidad de los trabajadores", en RODRÍGUEZ-PIÑERo Royo, Miguel y TODOLÍ SigneS, Adrián, (Directores): Vigilancia y control en el Derecho del Trabajo Digital, Pamplona (Thomson Reuters-Aranzadi), 2020, p. 349.

${ }^{28}$ Cabe apuntar que, en su momento, se valoró también la posibilidad de alojar este contenido dentro de un texto de desarrollo reglamentario [en términos similares a lo que, por ejemplo, el reciente Real Decreto 902/2020, de 13 de octubre (BOE $n^{\circ} 272$, de 14 de octubre), hace con la igualdad retributiva entre mujeres y hombres]. No obstante, y sin que ello quiera dar a entender que, necesariamente, se trata de una materia dotada de una mayor relevancia, al final se ha considerado más idónea la alternativa de incluir una regulación detallada en el articulado del ET, en la línea de esa voluntad tantas veces declarada de actualizar sus previsiones con al menos una pátina de modernidad. 
la práctica de la garantía ${ }^{29}$. Todo cuanto precede sin soslayar tampoco la trascendencia adquirida, dada su estrecha conexión, por la adecuada tutela de la intimidad del personal (en sus múltiples dimensiones), cuya explicitación serviría asimismo como refuerzo.

Obviamente, lo anterior convertiría en redundante al menos parte del artículo 20 bis del ET. Por eso y dado que se estima que no es este último el emplazamiento más idóneo para su contenido, el precepto debería desaparecer, quedando la redacción del cuarto de la siguiente manera:

\section{Artículo 4. Derechos laborales}

[...]

2. En la relación de trabajo, los trabajadores tienen derecho:

$[\ldots]$

h) A la desconexión digital y al desarrollo de acciones de formación y sensibilización sobre un uso responsable de las tecnologías de la información y la comunicación.

i) A la intimidad en el uso de los dispositivos digitales puestos a su disposición por el empleador, así como frente al uso de mecanismos de videovigilancia y geolocalización, en los términos establecidos en la legislación vigente en materia de protección de datos personales y garantía de los derechos digitales.

j) A cuantos se deriven específicamente del contrato de trabajo.

Avanzando en el articulado y siguiendo el orden numérico del ET, mayor enjundia reviste la segunda de las propuestas a realizar, consistente, conforme se adelantó, en insertar una original sección 6 en el Capítulo II de su Título I, denominada, en consonancia con el artículo 88 de la LOPDPGDD, "Derecho a la desconexión digital en el ámbito laboral" e integrada por un total de cinco preceptos (del 39 al 43 ET). Dicho sea de paso, este proceder conllevaría la necesidad de renumerar las disposiciones siguientes, lo cual, no obstante, y por razones de practicidad, se obviará en este artículo (donde no tendrá lugar dicha revisión sobre el ordinal de los contenidos posteriores).

En concreto, se considera que la norma debe comenzar por facilitar una concepción clara y cabal de la garantía a la que habrá que añadir previsiones sobre ciertos aspectos conexos, con los que terminar de clarificar y redondear el conjunto de cuestiones concurrentes como los tiempos de descanso, la disponibilidad, la fuerza mayor, las circunstancias excepcionales, la intimidad, la conciliación y la prevención de los daños

\footnotetext{
29 “De este prisma, son esenciales los convenios colectivos que regulan protocolos de actuación para garantizar que los trabajadores desconecten "digitalmente” de su trabajo", tal y como señala TRUJILLO PONS, Francisco, "El ejercicio del derecho a desconectar digitalmente del trabajo: su efectividad en las empresas", ob cit., p. 44.
} 
en la salud- de la que hoy carece, la cual ha de servir como punto de referencia preciso para las empresas, los empleados y sus respectivos interlocutores. Así, mediante un novedoso artículo 39, titulado Definiciones (similar, en planteamiento, a lo que por ejemplo hace el precepto número 4 de la LPRL), cabría prever que:

\section{"Artículo 39. Definiciones}

A efectos de la presente ley y de las normas que la desarrollen, se entenderá por: 1. "Desconexión digital": el derecho de toda persona trabajadora a disponer libremente de sus tiempos de descanso, de manera tal que durante dichos períodos, salvo en supuestos de disponibilidad pactada, de fuerza mayor o motivados por circunstancias excepcionales debidamente justificadas, no experimente injerencias laborales a través de dispositivos o herramientas digitales, posibilitando así el descanso, la intimidad, la conciliación de sus vidas personal, familiar y profesional, y la prevención de posibles daños en la salud vinculados a un uso prolongado o excesivo de aquellos.

2. "Tiempo de descanso": todo período, aun de disponibilidad, durante el cual la persona trabajadora no se encuentre en ejercicio de su actividad o de sus funciones profesionales.

3. " "Tiempo de disponibilidad": todo período durante el cual la persona trabajadora, a pesar de no estar obligada a permanecer en su lugar de trabajo, deba encontrarse localizable para atender posibles requerimientos profesionales. 4. "Tiempo de trabajo efectivo": todo período durante el cual la persona trabajadora se encuentre en ejercicio de su actividad o de sus funciones profesionales."

Conforme es de razón defender, "el nuevo derecho a la desconexión digital no es un derecho que tenga autonomía propia y diferenciada, sino que viene a aglutinar una serie de derechos y principios fundamentales tales como el derecho de intimidad, el derecho de conciliación de la vida personal y laboral y el derecho a la salud (derecho al descanso) ya reconocidos en nuestro ordenamiento jurídico" ${ }^{30}$. Es en razón a lo expuesto por lo que una definición de carácter omnicomprensivo como la planteada quizás responda mejor a la propia caracterización de la garantía. Lo cual podrá verse reforzado con una certera acotación de cada uno de los tiempos asociados a un desempeño laboral (de trabajo, de descanso y de disponibilidad). Al fin y a la postre, el derecho a la desconexión digital "supone, en el ámbito laboral [...], garantizar el

\footnotetext{
30 "Se podría decir entonces que es un derecho "escoba" en el sentido que tiene un contenido amplio y envolvente ya que arrastra consigo un grupo de derechos a los que representa". El argumento, en MuÑoz RuIZ, Ana Belén, "El derecho a la desconexión digital", Trabajo y Derecho, no extr. 12, 2020, p. 6 (versión digital).
} 
derecho al descanso en cualquier momento que no sea tiempo de trabajo y el derecho a la intimidad, ambos protegidos constitucionalmente" 31 .

Acto seguido, mediante otro precepto, correspondería incorporar a la norma un conjunto de disposiciones específicas en torno a la garantía, con las que no solo complementar el concepto recogido en el artículo precedente, sino también expresar con claridad su naturaleza o la íntima conexión que presenta con otras cuestiones relevantes, como la intimidad, la conciliación, el trabajo a distancia o el teletrabajo. De este modo:

"Artículo 40. Derecho a la desconexión digital

1. Con carácter general, para preservar su intimidad fuera del ámbito laboral, favorecer la conciliación de sus vidas personal, familiar y profesional, y garantizar que sean respetados sus períodos de descanso, todas las personas trabajadoras tendrán derecho a la desconexión digital, lo que les asegurará quedar liberadas de cualquier injerencia empresarial o profesional más allá del tiempo de trabajo legal, convencional o contractualmente establecido.

2. Asimismo, cuando impliquen el uso con fines laborales de herramientas tecnológicas, este derecho se preservará en los supuestos de realización total o parcial del trabajo a distancia.

3. No obstante, el ejercicio de este derecho podrá ser objeto de adaptación conforme a lo dispuesto en el convenio colectivo de aplicación, la política interna de la empresa o, en su defecto, el contrato de trabajo.

Dicha modulación habrá de derivar de un pacto de disponibilidad suscrito con la persona trabajadora o resultar precisa como consecuencia de situaciones de fuerza mayor, emergencia, urgencia o perjuicio grave, imprevisible e inminente para la empresa. En todo caso, el tiempo invertido en tales supuestos será considerado como de trabajo efectivo.

4. Las posibles modalidades en el ejercicio del derecho atenderán de manera particular a la naturaleza y al objeto de la relación laboral y, en todo caso, se ajustarán a lo establecido a través de la negociación colectiva."

Sobre este particular, interesa destacar que, dada la amplia variedad de situaciones susceptibles de presentarse en la práctica, se antoja recomendable contemplar dos posibles escenarios elementales: uno de índole general, al que respondería un reconocimiento básico y universal del derecho; otro específico, para el que prever hipotéticas adaptaciones en la materialización de la garantía (que no en su contenido o esencia), acordes con presumibles circunstancias justificativas a detallar a través de la

\footnotetext{
${ }^{31}$ Aguilar Martín, María Carmen, "El tiempo de trabajo como elemento vertebrador de la seguridad y la salud de las personas trabajadoras", Revista de Trabajo y Seguridad Social (CEF), n 456, 2021, p. 93.
} 
negociación colectiva, la preceptiva política interna a nivel empresarial o, en defecto de todo lo anterior, el contrato laboral suscrito.

A continuación, el texto legal habrá de dotar de contenido a dos elementos esenciales, en íntima conexión. El primero, el diagnóstico preliminar que, a partir de un análisis cualitativo, permita a la organización productiva obtener información precisa acerca de sus posibles necesidades en la materia. El segundo, derivado del anterior, la política interna sobre desconexión digital a elaborar por la empresa previa audiencia (así lo marca el artículo 88 de la LOPDPGDD) y, se estima conveniente, negociación con los representantes del personal. De este modo:

\section{"Artículo 41. Diagnóstico preliminar}

1. Antes de elaborar su política interna sobre desconexión digital, la empresa efectuará un diagnóstico preliminar al respecto, para lo cual desarrollará un análisis particularizado en el que habrá de considerar especialmente aspectos como las modalidades de disponibilidad de las personas trabajadoras y sus respectivas jornadas laborales, o los obstáculos y dificultades que puedan existir de cara a la efectiva aplicación del derecho a la desconexión digital del personal a su servicio.

2. La representación unitaria del personal deberá ser consultada, con una antelación mínima de diez días, antes de la ejecución de este diagnóstico preliminar. Con esta misma antelación tendrá que ser consultada cuando el diagnóstico deba repetirse de acuerdo con lo previsto en el apartado 4 de este artículo.

3. El resultado del diagnóstico preliminar será comunicado a los representantes unitarios del personal, que quedarán facultados para emitir un informe al respecto, o, en defecto de los anteriores, a las propias personas trabajadoras.

4. El empresario realizará controles periódicos sobre el grado de cumplimiento de las disposiciones legales, convencionales o internas en materia de desconexión digital. En todo caso, el diagnóstico deberá repetirse si se producen cambios sustanciales en determinadas circunstancias, como la organización del trabajo o el modo de ejecución de la actividad laboral por las personas trabajadoras a su servicio.

5. A partir de los resultados obtenidos tras el diagnóstico preliminar o sus posteriores revisiones, la empresa elaborará o actualizará el contenido de su política interna en materia de desconexión digital."

Evidentemente, este diagnóstico preliminar (inicial o periódico) presenta una destacada relevancia, pues sirve de antesala cualificada para la preceptiva política interna a desarrollar por la empresa, a la que proporcionará una información de indudable 
trascendencia práctica. Por razón de lo expuesto, se antoja más que recomendable la previa consulta a los representantes del personal, llamados a participar y a cooperar desde un principio en cuanto rodea a la materialización efectiva del derecho a la desconexión digital en las organizaciones productivas.

Por tal motivo, la regulación legal en torno a la política interna también ha de plasmar ese planteamiento, de ahí que, entre otros aspectos, también debe apostar por un previo, formal e imperativo período de consultas con los representantes del personal (para el que bien puede servir como referencia el contemplado por el ET para una modificación sustancial de condiciones laborales de carácter colectivo). Todo cuanto precede sin descuidar, además, la enunciación de un contenido mínimo imprescindible y de un conjunto de obligaciones básicas derivadas. Así:

\section{"Artículo 42. Política interna sobre desconexión digital}

1. La política interna a establecer por la empresa garantizará el ejercicio efectivo del derecho a la desconexión digital por las personas trabajadoras.

2. Para su elaboración, se deberán tomar como referencia los resultados obtenidos en el preceptivo diagnóstico preliminar. Asimismo, será necesario desarrollar un previo período de consultas con los representantes de los trabajadores, según lo previsto en el artículo *** de esta ley ${ }^{32}$.

3. El documento en el que finalmente se refleje la política interna de la empresa sobre desconexión digital incluirá, respecto de esta, el contenido mínimo siguiente:

a) Justificación.

b) Objetivos perseguidos.

c) Definiciones.

d) Garantía básica reconocida y su posible adaptación ante determinadas circunstancias.

e) Modalidades de ejercicio del derecho.

f) Medidas concretas a adoptar para la efectividad del derecho.

g) Recursos humanos, financieros y materiales necesarios.

h) Sistema de seguimiento, evaluación y actualización de la política interna sobre desconexión digital.

\footnotetext{
${ }^{32}$ Se está haciendo referencia en este momento al contenido del actual artículo 41.4 del ET, relativo al período de consultas propio de una modificación sustancial de condiciones laborales de carácter colectivo. No obstante, en atención a la necesidad previamente apuntada de renumerar los preceptos posteriores (que, como consecuencia de la incorporación en el texto legal de las novedosas propuestas, por fuerza verán modificados sus ordinales) y a la conveniencia práctica de no reflejar tal actualización en el cuerpo de este artículo (para así facilitar una más sencilla identificación por parte del lector de los aspectos a los aspectos a los que quepa hacer referencia), se ha preferido optar por los asteriscos en lugar de por precisar el canon legal al que se remite esta previsión.
} 
i) Vigencia, que no podrá ser superior a cuatro años.

3. Sin perjuicio de las demás obligaciones formales que puedan preverse en el marco de la negociación colectiva o en los acuerdos particulares alcanzados con los representantes de los trabajadores, una vez aprobada su política interna de desconexión digital la empresa deberá:

a) Informar por escrito a las personas trabajadoras afectadas acerca de su derecho a la desconexión digital y de los términos concretos en los que se ha de desarrollar esta garantía.

b) Formalizar con ellas un compromiso escrito en virtud del cual las personas trabajadoras, en su actividad laboral, se comprometan a utilizar de un modo racional y adecuado los medios e instrumentos tecnológicos facilitados por la empresa, que se abstendrán de emplear para fines profesionales durante sus períodos de descanso, vacaciones y permisos, salvo de concurrir alguno de los supuestos excepcionales previstos legal o convencionalmente.

c) Desarrollar acciones periódicas de formación y sensibilización en favor de las personas trabajadoras sobre el uso responsable de las tecnologías de la información y la comunicación."

En particular, se estima oportuna una previsión expresa y separada acerca de las acciones de formación y sensibilización dirigidas a las personas trabajadoras en relación con el uso responsable de las tecnologías de la información y la comunicación, cuya contribución a la prevención de ciertos riesgos profesionales, como el de la fatiga informática ${ }^{33}$, resulta incontrovertible. $\mathrm{Y}$ si bien se trata de una cuestión a concretar también en el marco de la negociación colectiva, la norma legal podría contener unas mínimas prescripciones al respecto. En consecuencia, se propone un precepto específico con el siguiente tenor literal:

“Artículo 43. Acciones de formación y sensibilización en favor de las personas trabajadoras

\footnotetext{
33 "Es fundamental el recurso a las acciones de formación y sensibilización sobre un uso razonable de los dispositivos digitales, esto es, educar en el uso de las nuevas tecnologías y sus riesgos", según remarca SERRANO ARGÜESO, Mariola, ““'Alwayson”. Propuestas para la efectividad del derecho a la desconexión digital en el marco de la economía 4.0", Revista Internacional y Comparada de Relaciones Laborales y Derecho del Empleo, n 2, 2019, p. 188 y 189.

En este sentido, "la monotonía, la falta de feedback en la realización de las tareas, quizás una falta de formación en competencias digitales, la falta de medios informáticos para desarrollar bien las tareas encomendadas, la confusión entre el principio y el fin tanto de la tarea como del horario son factores de riesgos que pueden ocasionar graves daños en la salud", según expone AGUILAR MARTíN, María Carmen, "El tiempo de trabajo como elemento vertebrador de la seguridad y la salud de las personas trabajadoras", $o b$ cit., p. 94.
} 
1. De manera periódica y de conformidad con su política interna en la materia, el contenido del convenio colectivo aplicable o los posibles acuerdos alcanzados con los representantes de los trabajadores, las empresas desarrollarán en favor de su personal, con medios propios o concertados, acciones de formación y sensibilización en relación con la desconexión digital y el uso responsable para fines profesionales de las tecnologías de la información y la comunicación. En ellas se prestará además una especial atención a los riesgos que, de lo contrario, podrían derivarse para la seguridad y la salud laborales.

2. Sin perjuicio de lo anterior, dicha formación deberá proporcionarse en el momento de incorporación de la persona trabajadora a la empresa y cuando se produzcan cambios en los medios o en las tecnológicas utilizadas en la actividad laboral."

Por otra parte, y concluyendo ya con el texto estatutario, toda vez que en la regulación legal sobre el diagnóstico preliminar y la política interna se atribuyen nuevas competencias a los representantes de los trabajadores, deviene precisa una puntual actualización de su artículo 64, relativo a los derechos de información y consulta del comité de empresa (y, por ende, de los delegados del personal ${ }^{34}$ ). En resumidas cuentas, la nueva versión del precepto señalaría lo siguiente (de nuevo, se resaltan en negrita las modificaciones operadas):

"Artículo 64. Derechos de información y consulta y competencias [...]

7. El comité de empresa tendrá también las siguientes competencias:

$[\ldots]$

e) Ser consultado por la empresa con carácter previo a la elaboración o revisión del preceptivo diagnóstico en materia de derecho a la desconexión digital, así como emitir un informe valorativo acerca de su contenido final.

f) Informar a sus representados en todos los temas y cuestiones señalados en este artículo en cuanto directa o indirectamente tengan o puedan tener repercusión en las relaciones laborales."

\section{Incisos digitales en la normativa de prevención de riesgos laborales}

Desde siempre, la salud en el trabajo se ha puesto en relación (y lo seguirá haciendo en el futuro) con las innovaciones coetáneas en cuanto a la forma de desarrollar la actividad laboral, el contenido de los puestos de trabajo, la realización de las tareas e, incluso, el entorno dentro del cual estas son llevadas a cabo. No en vano, se trata de "un

\footnotetext{
${ }^{34}$ Recuérdese que, según el artículo 62.2 del ET, "los delegados de personal [...] tendrán las mismas competencias establecidas para los comités de empresa".
} 
principio y derecho fundamental para lograr un futuro del trabajo más idóneo" "35, así como para propiciar el bienestar en el ámbito productivo ${ }^{36}$.

Por otra parte, la oportunidad de reflejar el derecho a la desconexión digital en el LPRL viene de la mano del artículo 88.3 de la LOPDGPDD, precepto que, de un modo expreso, alude a uno de los principales riesgos que para la salud del personal puede derivarse de un uso irrazonable de las herramientas tecnológicas: la "fatiga informática" ${ }^{37}$. Por consiguiente, es evidente que los potenciales factores lesivos "habrán de ser evaluados [...] -y- quedar sujetos al sistema de prevención de riesgos laborales" $" 38$.

A este respecto, bastaría con incorporar unas sucintas y puntuales actualizaciones en la normativa de referencia, que además servirían para corregir "la ignorancia del legislador digito laboral"39, quien en su momento obvió cualquier mínima revisión del texto que tiene por objeto natural "promover la seguridad y la salud de los trabajadores

35 OIT: Informe de la Comisión Mundial sobre el futuro del trabajo. Trabajar para un futuro más prometedor, 2019, p. 40 (disponible en: https:/www.ilo.org/wcmsp5/groups/public/---dgreports/--cabinet/documents/publication/wcms_662442.pdf,_fecha de la consulta: 24.10.2021). Al respecto de dicho documento, Fumero Dios, Inmaculada Sandra, "El informe de la Comisión Mundial sobre el futuro del trabajo y el propósito de reconocer la seguridad y salud en el trabajo como un derecho fundamental por la OIT”, Trabajo y Derecho, n 55, 2019, p. 2 (versión digital).

${ }^{36}$ RAMOS QuINTANA, Margarita Isabel, “Actos de violencia y estrés en el trabajo: análisis jurídico y marco europeo de prevención y protección”, Revista Trabajo y Seguridad Social (CEF), n 421, 2018, p. 31.

${ }^{37}$ Sobre el particular, MIÑARRO YANINI, Margarita: "El sistema de prevención de riesgos laborales como garantía de efectividad del derecho a la desconexión digital", ob cit., p. 579.

Es más, "dada la conexión del tiempo de trabajo con la seguridad y salud en el trabajo, la tendencia actual es a una interpretación garantista expansiva, lo que resulta hoy de especial utilidad ante los cambios recientes del empleo y la organización del trabajo, como sería su amplia "colonización digital". Lo que exigirá, para evitar la fatiga informática (artículo 88 [...] -LOPDGDD- y 18 [...] -RDL-28/2020[...]), el reconocimiento de interrupciones periódicas más habituales". El apunte, en MoLINA NAVARRETE, Cristobal, "Escenarios modernos de los tiempos de trabajo (y vida): actualidad (social y judicial) de un clásico en busca de su (¿imposible?) "soberanía"”, Revista de Trabajo y Seguridad Social $(C E F), \mathrm{n}^{\circ} 456,2021$, p. 105.

${ }^{38}$ Específicamente, "a nadie se le escapa que el tiempo de trabajo y la seguridad y salud deben ser elementos inseparables de las relaciones de trabajo [...]. Por todo ello, es importante encontrar un justo equilibrio entre intereses de [...] -empresarios y trabajadores-". Advirtiéndolo, AGUILAR MARTíN, María Carmen, "El tiempo de trabajo como elemento vertebrador de la seguridad y la salud de las personas trabajadoras", ob cit., p. 68.

Destacando también que el de la desconexión digital es "un derecho íntimamente vinculado con la prevención de salud de los trabajadores y protección del descanso", MARTÍNEZ MOYA, Juan, "El derecho a la desconexión digital: contenido, límites y limitaciones", Revista de Jurisprudencia Laboral, $\mathrm{n}^{\circ} 1$, 2021, p. 1 (versión digital).

${ }^{39}$ MiÑARro YAnini, Margarita y Molina NAVARrete, Cristobal, "El Estatuto de los Trabajadores, 40 años de "reformas” y “maquillados”: ¿una conmemoración con sabor a despedida?”, ob cit., p. 17. 
mediante la aplicación de medidas y el desarrollo de las actividades necesarias para la prevención de riesgos derivados del trabajo" (artículo 2). Entre ellos se encuentran, sin duda, los relacionados con la ausencia de una adecuada desconexión digital, que también han de quedar encuadrados dentro del genérico deber de protección que recae sobre el empleador (correlativo derecho del personal a su servicio ${ }^{40}$ ), impelido, junto con otras circunstancias, a adoptar cuantas medidas resulten precisas para adecuar la política preventiva de la empresa "a las modificaciones que puedan experimentar las circunstancias que incidan en la realización el trabajo" (artículo 14.2). A tal fin, como uno de los principios rectores a observar, "debe tener en cuenta la evolución de la técnica" [artículo 15.1.e)], que configura sus responsabilidades en la materia "de manera dinámica y en continua evolución" $"$.

En concreto y a los efectos de lo que en este artículo más interesa, las sucintas propuestas a realizar pasarían por reforzar la regulación estatutaria de la garantía mediante una ligera puesta al día de los preceptos referidos al genérico deber del patrono de proteger a su personal frente a los peligros presentes o latentes en el entorno productivo (artículo 14), la formación en materia preventiva con la que corresponde garantizar que cada uno de los empleados reciba, preferentemente dentro de la jornada laboral, una formación teórica y práctica suficiente y adecuada para garantizar su protección frente a los riesgos laborales (artículo 19), las obligaciones a asumir por los propios trabajadores con la obligación de cumplir con las medidas de prevención, por su propia seguridad y salud (artículo 29) y, las competencias y facultades de los delegados de prevención como uno de los protagonistas en este ámbito (artículo 36), por ser artículos -sobre el resto que ya contenían los mínimos- que han necesitado una mayor concreción.

Comenzando con el primero de ellos, bastaría con un retoque puntual, aunque significativo, a los efectos de dejar también aquí constancia expresa acerca de la segura y natural evolución de los riesgos profesionales en el tiempo y por obra de las distintas circunstancias concurrentes (por ejemplo, la generalizada utilización de las TIC). De este modo (se resaltan en negrita las modificaciones):

\section{"Artículo 14. Derecho a la protección frente a los riesgos laborales}

1. Los trabajadores tienen derecho a una protección eficaz en materia de seguridad y salud en el trabajo, la cual, en particular, habrá de tener en cuenta la aparición de nuevos riesgos o la transformación de los ya existentes."

\footnotetext{
${ }^{40}$ Exposición de motivos 5 de la LPRL.

${ }^{41}$ Mella MÉndez, Lourdes, "Los retos de la prevención de riesgos laborales ante la digitalización de la empresa y las nuevas formas de trabajo: puntos críticos", Revista Española de Derecho del Trabajo, $\mathrm{n}^{\circ}$ 229, 2020, p. 2 (versión digital).
} 
Conveniente resulta, asimismo, una somera revisión del precepto número 19 de la LPRL, relativo a la formación de los trabajadores en materia de seguridad y salud; el cual, necesariamente, ha de ser vinculado con el inédito artículo 43 del ET sugerido en este artículo. No en vano, en este último se alude a "acciones de formación y sensibilización en relación con la desconexión digital y el uso responsable para fines profesionales de las tecnologías de la información y la comunicación [...] -entre las que- se prestará [...] una especial atención a los riesgos que, de lo contrario, podrían derivarse para la seguridad y la salud laborales". Por consiguiente, se propone la siguiente redacción para su primer apartado:

\section{"Artículo 19. Formación de los trabajadores}

1. En cumplimiento del deber de protección, el empresario deberá garantizar que cada trabajador reciba una formación teórica y práctica, suficiente y adecuada, en materia preventiva, tanto en el momento de su contratación, cualquiera que sea la modalidad o duración de ésta, como cuando se produzcan cambios en las funciones que desempeñe o se introduzcan nuevas tecnologías o cambios en los equipos de trabajo.

La formación deberá estar centrada específicamente en el puesto de trabajo o función de cada trabajador, adaptarse a la evolución de los riesgos y a la aparición de otros nuevos y repetirse periódicamente, si fuera necesario.

Asimismo, cuando resulte preciso, el empresario desarrollará en favor de las personas trabajadoras a su servicio acciones de sensibilización sobre un uso responsable de las tecnologías de índole digital, de acuerdo con lo previsto en el artículo 43 del Estatuto de los Trabajadores."

Siguiendo la misma línea de intensificación que guía la revisión de la norma preventiva, su artículo 29, centrado en las responsabilidades de los empleados en el marco de la seguridad y la salud en los entornos productivos (que, asimismo, han de ser actualizadas), también podría recibir un leve pero expresivo aderezo, a través del cual incorporar la siguiente previsión al listado ejemplificativo de deberes recogido en su apartado $2.1^{\circ}$ :

“Artículo 29. Obligaciones de los trabajadores en materia de prevención de riesgos

[...]

2. Los trabajadores, con arreglo a su formación y siguiendo las instrucciones del empresario, deberán en particular:

1. Usar adecuada, razonable y responsablemente, de acuerdo con su naturaleza y los riesgos previsibles, las máquinas, aparatos, herramientas, 
sustancias peligrosas, equipos de transporte, tecnologías de la información y la comunicación y, en general, cualesquiera otros medios con los que desarrollen su actividad."

Para finalizar y en términos concordantes a lo hecho con los representantes unitarios del personal en el ET, restaría dirigir la mirada hacia sus, permítase la expresión (pues, pese a todo, son lógicas y acusadas las diferencias existentes entre unos y otros), "análogos" en el contexto de la seguridad y la salud laborales, los delegados de prevención ${ }^{42}$, cuyo ámbito material de actuación ha de ser completado en consonancia. Por consiguiente (las novedades constan en negrita):

“Artículo 36. Competencias y facultades de los Delegados de Prevención

1. Son competencias de los Delegados de Prevención:

$[\ldots]$

c) Ser consultados por el empresario, con carácter previo a su ejecución, acerca de las decisiones a que se refiere el artículo 33 de la presente Ley ${ }^{43}$. En especial, de cara a la elaboración del diagnóstico preliminar sobre desconexión digital previsto en el artículo 41 del Estatuto de los Trabajadores."

\section{Conclusiones}

El uso extensivo de las TIC en el mundo laboral contemporáneo genera retos que han de ser adecuadamente afrontados, en particular, mediante el establecimiento de una serie de garantías específicas que puedan tutelar ciertos derechos de las personas trabajadoras, como, entre otros, los de la protección de sus datos o a de su intimidad fuera del ámbito laboral.

Y si bien es cierto que lo hace con unas elevadas dosis de generalidad, a la LOPDPGDD hay que reconocerle el mérito de haber establecido unas pautas básicas a este respecto. No obstante, conviene insistir, se trata de un marco regulador deficitario, capaz de cuanto menos entorpecer la aplicación efectiva de sus previsiones.

\footnotetext{
${ }^{42} \mathrm{Al}$ fin y al cabo, "los delegados de prevención son los representantes de los trabajadores con funciones específicas en materia de prevención de riesgos en el trabajo" (artículo 35.1 de la LPRL).

${ }^{43}$ Recuérdese que dicho precepto señala, entre otras cuestiones, que "el empresario deberá consultar a los trabajadores, con la debida antelación, la adopción de las decisiones relativas a [...] la introducción de nuevas tecnologías -entre las que, desde luego, cabe incluir las de índole digital-, en todo lo relacionado con las consecuencias que éstas pudieran tener para la seguridad y la salud".
} 
Para solventarlo, se estima necesaria una intervención activa y coordinada, aunque por fuerza ajustada a sus respectivos ámbitos de actuación, del legislador, a quien corresponde perfilar con mayor precisión las actuales bases mínimas establecidas; del empresario, responsable de asegurar que todos los integrantes de la organización productiva respeten las garantías digitales del personal; y de los representantes legales de los trabajadores, llamados a utilizar oportuna y convenientemente su capacidad negocial.

Si bien antes de la plasmación efectiva del derecho a la desconexión digital en el artículo 88 de la LOPDPGDD (y, posteriormente, en el artículo 20 bis del ET) ya cabía hablar de la existencia de una normativa legal y convencional capaz de limitar las intromisiones profesionales durante los tiempos de descanso, su carácter inespecífico unido a la vertiginosa evolución y extensión de las TIC evidenció la necesidad de brindarle una atención particularizada.

Sin embargo, la de la LOPDPGDD supone una regulación que cabe calificar de excesivamente programática, inacabada y, en consecuencia, insuficiente. Y ello por más que quepa reconocer el importarte papel que, al respecto, también han de representar la negociación colectiva (al menos en aspectos tales como las acciones formativas y de sensibilización sobre el uso racional de las herramientas tecnológicas, o el control de los tiempos de trabajo) y, sobre todo (esa es la opción por la que se ha decantado el legislador), las políticas o protocolos internos a nivel de empresa.

En resumidas cuentas, aunque el actual entramado normativo en torno a la desconexión digital dota a la garantía de una razonable cobertura legal, no es menos cierto que aquel presenta ciertas deficiencias relevantes. Estas, en tanto en cuanto no se resuelvan mediante una deseable depuración de su regulación específica (la LOPDPGDD) o, inclusive, de una plasmación más acabada del derecho en el ET, habrán de ser abordadas en sede judicial (cuyos órganos, por cierto, cuentan ya con una apreciable doctrina en la materia, que seguro se irá incrementando con el paso del tiempo) o paliadas a través del socorrido recurso a la autorregulación colectiva (llamada, según ha sido apuntado, a adquirir un destacado protagonismo en la mejora del marco rector de referencia).

A este respecto, cabe afirmar que, gracias a las propuestas formuladas en este artículo, se lograría enmendar la insuficiente atención prestada en el ET al derecho a la desconexión digital. Esta garantía resulta merecedora de una mayor y mejor recepción en aquel, capaz de dar respuesta a las demandas de los contextos productivos del siglo XXI y de aportar, así, unas pautas básicas lo suficientemente detalladas acerca de sus contenidos o aspectos esenciales: desde su reconocimiento en el artículo 4 de la norma 
(por si alguna duda subsistiera), pasando por un concepto delimitado, hasta llegar a un desarrollo autónomo y pormenorizado, donde por fuerza han de sobresalir el diagnóstico preliminar, la política interna a elaborar por la empresa y las acciones de formación y sensibilización a favor del personal (cuyos representantes, dicho sea de paso, también están llamados a intervenir de manera notable).

Aunque esto ya no resulte tan apremiante, pero sí oportuno, ese marco normativo general puede ir acompañado de una tenue revisión de la LPRL, dirigida a reforzar el derecho a la desconexión digital en el concreto contexto de la seguridad y la salud en el trabajo. No en vano, constituyen materias que se encuentran estrechamente entrelazadas (sobre todo en unos entornos laborales día a día más tecnificados).

A su vez, las directrices emanadas del texto legal podrán proyectarse hacia abajo, en particular, hacia la negociación colectiva, responsable de adaptarlas a las particulares necesidades y circunstancias de cada sector o empresa (aunque no cuenten con representantes de los trabajadores) intentando, además, siempre y cuando ello resulte posible, mejorar lo dispuesto en la normativa de referencia.

\section{Bibliografía}

Aguilar Martín, María Carmen, "El tiempo de trabajo como elemento vertebrador de la seguridad y la salud de las personas trabajadoras", Revista de Trabajo y Seguridad Social (CEF), n 456, 2021, p. 65-100.

CABero Morán, Enrique, “¿Hacia un nuevo Estatuto de los Trabajadores?”, Trabajo y Derecho, $\mathrm{n}^{\circ}$ 55, 2019, p. 1-8 (versión digital).

Casas BaAmonde, María Emilia, "La significación principal del Estatuto de los Trabajadores en el ordenamiento laboral constitucional", Trabajo y Derecho, $\mathrm{n}^{\circ}$ 63, 2020, p. 1-25 (versión digital).

CRUZ Villalón, Jesús, "Hacia un nuevo Estatuto de los Trabajadores", Trabajo y Derecho, $\mathrm{n}^{\circ} 63,2020$, p. 1-22 (versión digital).

Cruz Villalón, Jesús, García-Perrote Escartín, Ignacio, Goerlich Peset, José María y Mercader UGuinA, Jesús Rafael, "La refundición del Estatuto de los Trabajadores de 2015", Actualidad Jurídica Aranzadi, no 916, 2016, p. 1-3 (versión digital). 
FERNÁNDEZ-COSTALES MUÑIZ, Javier, "La prevención de riesgos laborales y sus nuevas exigencias y retos frente al avance de la digitalización y las nuevas tecnologías", Revista de Trabajo y Seguridad Social (CEF), no 452, 2020, p. 83-115.

GARCÍA COCA, Olga, "El registro de la jornada laboral y la privacidad de los trabajadores", en AA.VV. (RODRÍGUEZ-PIÑERO ROYO, Miguel y TODOLÍ SIGNES, Adrián, (Directores): Vigilancia y control en el Derecho del Trabajo Digital, Pamplona (Thomson Reuters-Aranzadi), 2020, p. 327-351.

MARTÍNEZ MoyA, Juan, "El derecho a la desconexión digital: contenido, límites y limitaciones", Revista de Jurisprudencia Laboral, n 1, 2021, p. 1-11 (versión digital).

Mella MÉndez, Lourdes, "Los retos de la prevención de riesgos laborales ante la digitalización de la empresa y las nuevas formas de trabajo: puntos críticos", Revista Española de Derecho del Trabajo, n 229, 2020, p. 1-33 (versión digital).

MiÑARRo YANINI, Margarita, "La desconexión digital en la práctica negocial: más forma que fondo en la configuración del derecho", Revista de Trabajo y Seguridad Social (CEF), no 440, 2019, p. 5-18.

MiÑARRO YANINI, Margarita, "El sistema de prevención de riesgos laborales como garantía de efectividad del derecho a la desconexión digital”, en RODRÍGUEZ-PIÑERO Royo, Miguel y Rodolí Signes, Adrián (Directores), Vigilancia y control en el Derecho del Trabajo Digital, Pamplona (Thomson Reuters-Aranzadi), 2020, p. 577594.

MiÑARRO YANINI, Margarita, "La "transición tecnológica sociolaboralmente justa”: por una gobernanza colectiva de la digitalización", Revista de Trabajo y Seguridad Social $(C E F), \mathrm{n}^{\circ} 452,2020$, p. 5-16.

Miñarro Yanini, Margarita y Molina Navarrete, Cristobal, "El Estatuto de los Trabajadores, 40 años de "reformas" y "maquillados": ¿una conmemoración con sabor a despedida?", Revista de Trabajo y Seguridad Social (CEF), n 444, 2020, p. 5-21.

Molina NAVARrete, Cristobal, "Escenarios modernos de los tiempos de trabajo (y vida): actualidad (social y judicial) de un clásico en busca de su (¿imposible?) "soberanía"', Revista de Trabajo y Seguridad Social (CEF), no 456, 2021, p. 101-133.

MuÑoz RuIZ, Ana Belén, "El derecho a la desconexión digital", Trabajo y Derecho, n extr. 12, 2020, p. 1-28 (versión digital). 
PÉREZ CAMPOS, Ana Isabel, "Teletrabajo y derecho a la desconexión digital", Revista Internacional y Comparada de Relaciones Laborales y Derecho del Empleo, vol. 9, $\mathrm{n}^{\circ}$ 1, 2021, p. 1-528.

RAMOS QuinTANA, Margarita Isabel, “Actos de violencia y estrés en el trabajo: análisis jurídico y marco europeo de prevención y protección”, Revista Trabajo y Seguridad Social (CEF), no 421, 2018, p. 19-44.

SERrAno Argüeso, Mariola, ““'Alwayson”. Propuestas para la efectividad del derecho a la desconexión digital en el marco de la economía 4.0", Revista Internacional y Comparada de Relaciones Laborales y Derecho del Empleo, no 2, 2019, p. 164-191.

TrujiLlo Pons, Francisco, "El ejercicio del derecho a desconectar digitalmente del trabajo: su efectividad en las empresas", Lan Harremanak-Revista de relaciones laborales, $\mathrm{n}^{\circ} 44,2020$, p. 39 a 55.

TRUJILlo Pons, Francisco, "La desconexión digital en el trabajo. Un comentario a la luz de la sentencia del Tribunal Superior de Justicia de Madrid, de 4 de noviembre de 2020 (rec. 430/2020)", Revista de Derecho Social, no 92, 2021, p. 197-202. 